\title{
El juicio laboral entre el conflicto individual y el conflicto de clases. Aportes desde la justicia laboral platense
}

\section{Andres Stagnaro*}

Resumen: El presente artículo tiene como objetivo reflexionar sobre las características de los conflictos que se desarrollaban en los Tribunales del Trabajo de la ciudad de La Plata en sus inicios (1948-1955) a fin de dilucidar si se trataba de conflictos individuales o colectivos del trabajo. La hipótesis de trabajo se plantea desde una perspectiva que centra su desarrollo en la aplicación del concepto de agencia histórica como central para dilucidar las características colectivas en los conflictos individuales. A fin de sostener dicha hipótesis se presentaran los límites impuestos a la individualización desde la doctrina misma del Derecho Laboral, así como también el límite impuesto por las prácticas mismas de los actores que acudían a la justicia laboral en búsqueda de sus derechos. Esta indagación permite, además, reconstruir nuevos roles para instituciones como los sindicatos y su papel en los conflictos cotidianos.

Palabras clave: Justicia del Trabajo; conflicto; agencia histórica.

\begin{abstract}
This article aims to define whether the conflict that develops in the Labor Courts in La Plata city in its first years (1948-1955) was individual or collective. The working hypothesis arises from a perspective that focuses its development in the application of the concept of historical agency as central to elucidate the collective characteristics in individual disputes. In order to support this hypothesis it will be presented the limits to the individualization from Labor Law doctrine itself, as well as the limit imposed by the practices of the actors themselves who came to labor justice in pursuit of their rights. This research also allows reconstructing new roles for institutions such as trade unions and their role in everyday conflicts.
\end{abstract}

Keywords: Labor Justice; conflict; historical agency.

* IdIHCS-Conicet-Universidad Nacional de La Plata. Doutor en Historia pela Universidad Nacional de La Plata, profesor de Historia Americana Contemporánea. 


\section{Introducción}

La propuesta aquí presentada tiene como objetivo reflexionar en torno a algunos considerandos de orden teórico/metodológico sobre el tipo de conflicto que se ventilaban en los Tribunales del Trabajo de la ciudad de La Plata, ${ }^{1}$ capital de la provincia de Buenos Aires -el estado industrial más importante del paísen los comienzos de la justicia laboral durante los gobiernos peronistas. En tanto conflicto ventilado en la institución judicial, los enfrentamientos entre los trabajadores y sus patrones en esta instancia responden a una lógica institucional no exenta de contradicciones. Ésta busca colocar al trabajador individual frente a su patrón en un espacio que a priori se puede definir como pro obrero debido a las características propias del Derecho Laboral y la forma misma en que los Tribunales del Trabajo fueron concebidos, en donde prima la voluntad manifiesta de proteger a la parte más débil de la relación laboral.

La hipótesis a considerar es que a pesar de esta individualización institucional propuesta por los Tribunales del Trabajo, el conflicto en dicha instancia ventilado no puede ser considerado, al menos no exclusivamente, un conflicto de carácter individual, sino que por el contrario responde a una lógica más amplia de enfrentamiento entre el capital y el trabajo en el que la instancia judicial es una arena más del mismo conflicto. Por ese motivo no puede ser abordado desde un individualismo metodológico que intente explicar el mismo mediante la elección racional del individuo - en este caso el trabajador - aun cuando muchas veces sea el trabajador quien tome la decisión personal de acudir a la justicia laboral. Estos límites a la individualización serán observados tanto desde el marco normativo como desde las prácticas (jurídicas y legas) que llevan adelante los trabajadores.

Por otro lado también se hace necesaria una revisión de la idea misma de conflicto, ya que parte de la historiografía ha tendido a presentar las etapas conflictivas como el momento del enfrentamiento entre el capital y el trabajo de forma abierta y explícita. El conflicto, así, entre el capital y el trabajo recibió gran parte de la atención por parte de las ciencias sociales. Tanto algunos autores vinculados a las teorías marxistas como no marxistas han constituido a este conflicto en el eje de las disputas teóricas de la teoría social, al asumir que su comprensión otorga la clave para entender el cambio social. Dentro de los análisis históricos del conflicto entre los dos polos de la relación laboral se ha hecho foco fundamentalmente - aunque no de forma exclusiva - en las huelgas como momentos privilegiados para la observación empírica de dicho conflicto. Esta preeminencia de la huelga como objeto de la teoría social llevó las más de las veces a trazar un paralelismo entre actividad huelguística y conflictividad laboral, descartando otras formas de conflicto. Si bien no puede negarse la importancia de la huelga como expresión colectiva - y como formadora de ese colectivo - de la clase obrera, centrarse exclusivamente en la huelga conlleva el doble riesgo advertido por Hobsbawm, en primer lugar trazar una distinción demasiado tajante entre el conflicto abierto y otros tipos de conflicto, y en segundo lugar, se corre el riesgo de reproducir en parte el esquema de la clase alta de prestar atención exclusivamente a los conflictos violentos.

1 La ciudad de La Plata es la capital de la provincia de Buenos Aires desde que la federalización de la ciudad de Buenos Aires dejase al estado provincial homónimo sin capital en 1880. La ciudad fue creada expresamente para albergar los poderes provinciales el 19 de Noviembre de 1882. El funcionamiento de los Tribunales del Trabajo datan de 1949, mientras que la ley provincial 5178 es de fines de 1947, sancionada durante la gobernación del peronista Domingo Mercante. 
Esta presentación dará cuenta del conflicto pero en una perspectiva micro, ya que analizará el enfrentamiento entre trabajadores y empresarios particulares en el marco de una institución estatal, como lo es la Justicia del Trabajo de la provincia de Buenos Aires. La Justicia del Trabajo, como institución mediadora en las relaciones laborales, fue creada como producto de la voluntad política del peronismo por encontrar herramientas institucionales que garantizaran la concordia de las clases sociales en pugna mediante la garantía de la Justicia Social. En tal sentido constituyó un eslabón más en el elaborado entramado institucional del peronismo ${ }^{2}$ que reconfiguró incluso a instituciones previas como las comisiones de conciliación y arbitraje de la Secretaría de Trabajo y Previsión. ${ }^{3}$ Pero además de novedades institucionales en el ámbito estatal, el peronismo también configuró de forma novedosa el campo sindical argentino al dotar a los sindicatos de un lugar central en la mediación de los conflictos laborales. En tal sentido la constitución de sindicatos únicos por rama y legalizados por el Estado, nucleados en una única central, erigió al sindicalismo como un actor central del proyecto político peronista tendiente a incorporar a los trabajadores. Este reconocimiento de los sindicatos fue un proceso en que coincidieron altos niveles de movilización y afiliación sindical que favorecieron un desarrollo organizativo capaz de garantizar su nuevo rol. Las funciones sindicales se vieron así fortalecidas por el reconocimiento estatal. Éstas no fueron sólo la representación obrera en las instancias de negociación colectiva sino que como veremos incluyó también el fortalecimiento de funciones de asesoramiento a los trabajadores.

\section{El conflicto}

En la historiografía argentina la huelga constituye, con algunas excepciones, ${ }^{4}$ el foco de los trabajos sobre conflictividad obrera. Esta preeminencia tiene impactos sobre la forma en que se aborda la historia de los trabajadores. En primer lugar la elección de la huelga como momento fundamental del conflicto tiende a delimitar los momentos conflictivos según la un esquema basado en la cantidad de huelgas/ trabajadores y huelga/horas perdidas de cada período. Por lo general esta línea interpretativa va vinculada a diferentes debates sobre el grado de conciencia de la clase obrera - su conformación en tanto clase para si - y observa en el conflicto mismo la conformación de la clase y la estrategia desplegada en tanto clase. ${ }^{5}$

2 Sobre la trascendencia de los cambios en la organización estatal impuestas por el peronismo ver CAMPIONE Daniel. Los orígenes estatales del peronismo. Buenos Aires: Miño y Dávila, 2007.

3 La Secretaría de Trabajo y Previsión fue el antecedente del Ministerio de Trabajo y Previsión y el sucesor del Departamento Nacional del Trabajo. Además fue el organismo desde el que Juan Domingo Perón constituyó sus relaciones con los líderes sindicales.

4 En los últimos años se aprecia el avance en estudios centrados en la conflictividad obrera cotidiana en el interior del proceso productivo. Estos estudios han alumbrado los rasgos de conflictos laborales relacionados con la organización misma de la producción y las herramientas de la resistencia molecular de los trabajadores (por ejemplo el trabajo a desgano o a reglamento). Una buena síntesis de dichas perspectivas en DICÓSIMO, Daniel y SIMONASI, Silvia (comp.). Trabajadores y empresarios en la Argentina del siglo XX: indagaciones desde la historia social. Rosario: Prohistoria ediciones, 2011. También es interesante el desarrollo de los debates en torno a la organización de las comisiones internas de trabajadores en la medida en que permiten reconstruir las secuencias de los hechos que llevan a una huelga. Véase por ejemplo SCHIAVI, Marcos. "Organización y conflictividad textil: La Fábrica Argentina de Alpargatas a comienzos del primer gobierno peronista”, Mundos do Trabalho, v. $4 n^{\circ} 8,2012$. Disponible en https://periodicos.ufsc.br/index.php/mundosdotrabalho/issue/view/1901/showToc.

5 IÑIGO CARRERA, Nicolás. La estrategia de la clase obrera. 1936. Buenos Aires: Ediciones Madres de Plaza de Mayo, 2004; CONTRERAS, Gustavo N. "El peronismo obrero. La estrategia laborista de la clase obrera durante el gobierno peronista. Un análisis de la huelga de los trabajadores frigoríficos de 1950”, en PIMSA. 
Esta línea interpretativa comparte el interés - sobre todo por su insistencia en las características de la conciencia de clase - de una tradición a la hora de indagar sobre la historia obrera: la insistencia en las organizaciones formales de la clase (partidos políticos, pero fundamentalmente sus organizaciones gremiales). La existencia de estas instituciones legó a la historiografía una gran cantidad de fuentes - y en algunos casos interpretaciones como son los casos de historias del movimiento obrero escritas por militantes de las mismas organizaciones como Iscaro, Marotta, etc. - justamente en un campo que debe acarrear con la escasez de fuentes. Si bien el interés por la organización de la clase obrera entró en declive con la "renovación" que se propuso en la academia en los años ochenta del siglo pasado, la reacción al giro culturalista de la historia social renovó los interrogantes sobre la organización sindical y política de los trabajadores.

La referida "renovación" propuso indagar no ya en las instituciones formales - y por lo tanto dejó de lado preguntas sobre la conciencia - sino en la vida cotidiana y en las condiciones de vida y consumo de los trabajadores. El puntapié inicial fue la hipótesis de Gutiérrez y Romero ${ }^{6}$ que sostenía que las pautas de vivienda, consumo, y la alta movilidad social en las ciudades desdibujaba la identidad obrera en sectores populares en donde convivían trabajadores manuales, pequeños comerciantes y burócratas de los escalafones más bajos del servicio estatal. Sin clase obrera a la vista, la huelga como eje del conflicto - y la conflictividad misma fue reemplazado en la historia de entreguerras por la imagen de una sociedad armoniosa. Varios han sido los trabajos que rechazando esta perspectiva han dado cuenta de no sólo la existencia de una sociedad conflictiva, sino de la pervivencia y fortalecimiento de la clase obrera.?

De todas maneras algunas de las críticas del trabajo de Gutiérrez y Romero a las propuestas estructuralistas llevaron a otros caminos historiográficos. Desde el estudio de la vida dentro y fuera de la fábrica de los trabajadores se ha buscado no ya la imagen de una sociedad igualitaria y sin conflictos, sino la existencia de las distinciones de clase, la presencia de la cultura obrera en ámbitos fuera del lugar del trabajo y de las instituciones gremiales y políticas de la clase. La huelga, en esta perspectiva, es un elemento importante en el estudio de la clase obrera, pero no tiene ya el lugar preponderante en el análisis de la clase obrera. ${ }^{8}$

La huelga entonces, si bien ha perdido cierta relevancia a la hora de investigar sobre la historia de los trabajadores, sigue siendo el presentado como el momento de expresión del conflicto entre el capital y el trabajo. Tanto para justificar el conflicto como la ausencia del mismo, las investigaciones sobre los trabajadores (o los "sectores populares" en el caso de la armonía) hacen referencia a los ciclos de huelga. Sin ir en desmedro de dicha interpretación, el objetivo de este artículo

Documentos y Comunicaciones 2006, Buenos Aires, 2007 y NIETO Agustín, "Conflictividad obrera en el puerto de Mar del Plata: del anarquismo al peronismo. El Sindicato Obrero de la Industria del Pescado, 1942-1948", en Revista de Estudios Marítimos y Sociales, № 1, Mar del Plata, 2008, pp. 35-44.

6 GUTIERREZ, Leandro y ROMERO, Luis Alberto. Sectores populares, cultura y política. Buenos Aires en entreguerra. Buenos Aires: Sudamericana, 1995.

7 IÑIGO, CARRERA, Op. cit. Para una crítica del concepto de sectores populares ver CAMARERO, Hernán, "Consideraciones sobre la historia social de la Argentina urbana en las décadas de 1920 y 1930: clase obrera y sectores populares”. Nuevo Topo. Revista de Historia y Pensamiento Crítico, $N^{\circ} 4$, Buenos Aires, Septiembre/Octubre de 2007.

8 SURIANO, Juan. "Los dilemas actuales de la historia de los trabajadores". In: GELMAN Juan (comp.). La Historia económica argentina en la encrucijada. Balances y perspectivas. Buenos Aires: Prometeo Libros, 2006; LOBATO Mirta Zaida, La vida en las fábricas. Trabajo, protesta y política en una comunidad obrera, Berisso (1904-1970). Buenos Aires: Prometeo, 2004; de la misma autora: "Los trabajadores en la era del progreso", In El progreso, la modernización y sus límites t. V de la Nueva Historia Argentina, Buenos Aires: Sudamericana, 2000, pp. 467-505. 
es ahondar en otro tipo de conflictividad que adquiere un carácter permanente y permite así posar la mirada sobre lo que ocurre entre huelga y huelga, otorgando continuidad al proceso de conflicto, en línea con las nuevas indagaciones en torno a los conflictos moleculares. Esta conflictividad está además institucionalizada por fuera del establecimiento industrial, pero expresa el enfrentamiento entre el capital y el trabajo de manera directa con eje en el valor de la mano de obra - principalmente - pero sobre todo se trataba una pelea por la obtención y ampliación de derechos y control patronal de los establecimientos. Esta institucionalización desde ya evita que este tipo de conflicto tuviese como objetivo las transformaciones profundas de la sociedad, pero aun así refería a enfrentamientos que implicaban transformaciones en las relaciones entre el capital y el trabajo.

Estos conflictos serán observados a través de los juicios laborales de los Tribunales del Trabajo $n^{\circ} 1$ de la ciudad de La Plata, que conforman el corpus básico de fuentes. La creación de los Tribunales del Trabajo en la provincia de Buenos Aires mediante la Ley Provincial 5178 de 1947 sumó una nueva institución estatal dedicada a solucionar lo que desde principios de siglo XX se conocía como la Cuestión Social, cuyo eje lo constituía la cuestión obrera. ${ }^{9}$

\section{Colectivización e individualización del conflicto}

La creciente presencia mediadora estatal en el conflicto desde principios del siglo $X X,{ }^{10}$ con una mayor especialización en las instituciones puestas al servicio de atender el conflicto obrero, posicionaron a los trabajadores frente a un actor cuyos objetivos en el enfrentamiento no eran ya sólo el sometimiento de los trabajadores sino también del capital. Si la figura central que representaba al poder estatal en los conflictos a fines del siglo XIX y principios del XX era el comisario de policía, ${ }^{11}$ la creación del Departamento Nacional del Trabajo (en adelante DNT) y su creciente autonomía permitieron contar con una oficina especializada a la que los trabajadores podían recurrir en búsqueda de torcer la intransigencia patronal. ${ }^{12}$

9 SURIANO, Juan. “Introducción: Una aproximación a la definición de la cuestión social en Argentina”. In: SURIANO, Juan (comp.). La Cuestión Social en Argentina, 1870-1943. Buenos Aires: La Colmena, 2000.

10 La referencia a la presencia estatal es asumida aquí cuando el estado busca intervenir en el conflicto más allá de intervención meramente represiva.

11 La intervención del comisario de policía buscaba sin dudas mantener el orden, pero fue adquiriendo cada un rol mediador cada vez mayor, y aunque de manera informal, su intervención muchas veces era solicitada por los huelguistas HOROWITZ, Joel. Los sindicatos, el Estado y el surgimiento del peronismo, 1930/1946. Buenos Aires: Eduntref, 2004.

12 La bibliografía sobre el DNT es amplia y tiende a coincidir que después de los primeros años, en donde su función estaba más vinculada a la redacción de nueva legislación y a la conformación de datos estadísticos, logró constituirse este organismo como referencia obligada en el caso de existir conflicto entre los trabajadores y sus patrones. Si bien no siempre su intervención era efectiva en el logro de los reclamos obreros, la disposición de los funcionarios del organismo a escuchar a la fracción obrera los colocaba a los ojos de las organizaciones sindicales en un lugar central en el conflicto. SURIANO, Juan. "EI Departamento Nacional del Trabajo y la política laboral durante el primer gobierno de Hipólito Yrigoyen” In: PLOTKIN, Mariano Ben y ZIMMERMAN, Eduardo (comp.). Los Saberes del Estado. Buenos Aires: Edhasa, 2012; SOPRANO, Germán. “El Departamento Nacional del Trabajo y su proyecto de regulación estatal de las relaciones Capital-Trabajo en Argentina. 1907-1943”. In: PANETTIERI, José (comp.) Argentina: Trabajadores entre dos guerras. Buenos Aires: Eudeba, 2000; KORZENIEWICZ, Roberto. "Las vísperas del peronismo. Los conflictos laborales entre 1930 y 1943”. Desarrollo Económico, Vol 33, № 131, Buenos Aires: IDES, 1993. GAUDIO, Ricardo y PILONE, Jorge. "Estado y relaciones laborales en el período previo al surgimiento del peronismo, 1935-1943”. Desarrollo Económico, Vol. 24, № 94, Buenos Aires: IDES, 1984. 
El DNT fue constituyendo un espacio en donde las tres partes en conflicto se encontraban a resolver sus diferencias. Esta negociación era llevada adelante por representaciones colectivas: por un lado las dirigencias sindicales de los sindicatos legalmente reconocidos o que al menos era avalados desde el DNT, representantes de las asociaciones patronales, y representantes del estado encarnados en los funcionarios del DNT. Al igual que el impacto de las huelgas y las organizaciones gremiales, la importancia del DNT y, por su medio, del Poder Ejecutivo, llevó a la historiografía a interesarse especialmente en los conflictos que se llevaban ante este organismo, homologando las más de las veces al DNT como la expresión misma del Estado. Si bien algunas excepciones plantearon la necesidad de realizar un profundo análisis empírico a fin de buscar la heterogeneidad de la intervención estatal, la primacía de los estudios del DNT (y sus sucesores: la Secretaría de Trabajo y Previsión y el Ministerio de Trabajo y Previsión) llevó a prestar especial atención a los conflictos en los que este organismo era parte.

La intervención del Poder Ejecutivo en el conflicto entre el trabajo y el capital promovió la interpelación en términos colectivos. El Poder Ejecutivo se presentaba como el mediador en los aspectos conflictivos de la esfera pública ofreciendo su papel de árbitro en las disputas entre actores antagónicos. A fin de desarrollar este rol fue construyendo un entramado institucional cada vez más complejo por medio de las negociaciones con los actores envueltos (sindicales, patronales, profesionales, burocráticos). El Poder Ejecutivo, como mediador, cumplió su función en torno a lo que consideraba cuestiones de índole pública. Distintos factores intervenían en la elección de los actores habilitados para intervenir, sin dudas la aceptación por parte de los funcionarios estatales de los interlocutores obreros era fundamental para poder sentarse en la mesa de negociación.

Ser miembros de un sindicato con ideología afín a la intervención estatal y de cierto reconocimiento entre los trabajadores eran condiciones casi obligatorias. Si bien las relaciones eran establecidas casi de forma personal con funcionarios particulares, ${ }^{13}$ en términos formales el Estado presentaba las negociaciones como entre colectivos. Al reconocerlos, los dotaba de sentido para otros actores, pero al mismo tiempo los clasificaba por medio de sus propios mecanismos. Estos mecanismos no estaban exentos de pretensiones de control, pero lo más importante es remarcar el carácter clasificador que ejercía el Estado por medio del Poder Ejecutivo. Las instituciones dispuestas en el Poder Ejecutivo para lidiar con la cuestión social, a pesar de sus contradicciones y tensiones inherentes a la entidad estatal, funcionaron siempre en un orden en donde lo importante era la representación de corte corporativo. Incluso durante etapas de predominancia del liberalismo, la representación corporativa estaba presente.

Así, los conflictos surgidos de la relación laboral intentaron ser abordados mediante la sanción - como medida preventiva que legislaba en torno a esa misma relación - de convenios colectivos de trabajo entre los empresarios y los trabajadores de diferentes ramas de la industria. ${ }^{14}$ Las instancias de resolución de conflictos dentro del DNT - a pesar de no llegar a materializarse - eran pensadas en base a una representación corporativa, con delegados de las clases en conflicto. Tal vez un intento que buscó crear una institución con mayor autonomía de las clases sociales en disputa fue el del Dr. Armando Spinelli, quien fuese director del

13 HOROWITZ, Joel. Los sindicatos, el Estado y el surgimiento del peronismo, 1930/1946, Buenos Aires: Eduntref, 2004.

14 GAUDIO, Ricardo y PILONE, Jorge. op. cit.; KORZENIEWICZ, Roberto. op. cit. 
Departamento Provincial del Trabajo de la provincia de Buenos Aires. ${ }^{15} \mathrm{~A}$ pesar de que el gobierno del gobernador Fresco entra en las generales de un gobierno corporativista, Spinelli se erigió como verdadero árbitro en las disputas laborales individuales, ${ }^{16}$ aunque a esta tarea dedicó menos tiempo que a congeniar la relación con los gremios y las asociaciones patronales.

Al ser la intervención pensada en términos de evitar o solucionar -según el caso- disrupciones del orden público, los conflictos en los que intervenía el DNT eran de carácter similar a aquellos advertidos por Hobsbawm ${ }^{17}$ ya señalados. Sin embargo la conflictividad entre el trabajo y el capital no se limita a los conflictos que se expresan en las irrupciones al espacio público como lo son las huelgas y las manifestaciones, o a los conflictos fabriles de gran escala. La relación misma entre capital y trabajo implica la existencia de conflicto en la medida en que sus actores cargan con intereses antagónicos. El enfrentamiento no se reduce a aquellos que tienen a los sindicatos y las asociaciones patronales como actores sino que se reproduce en cada relación entre patrón y trabajador. En este sentido, si la intervención del Poder Ejecutivo lograba imponer marcos al conflicto (sanción de convenios colectivos, multas a empresas y sindicatos, establecimiento de la legalidad o ilegalidad de las huelgas) y el Poder Legislativo avanzaba - aunque lentamente ${ }^{18}$ - en la sanción de marcos regulatorios a la relación laboral, el cumplimiento de toda esta batería de medidas en los casos concretos encontraba ciertas dificultades de aplicación.

En este contexto la llegada de Perón al poder, apoyado por gran parte de la clase obrera y muchas de sus organizaciones sindicales ${ }^{19}$ implicó un gran respaldo para los que abogaban por la creación dentro del Poder Judicial del fuero laboral. La justicia del trabajo fue creada para el ámbito nacional (con jurisdicción solamente sobre la ciudad de Buenos Aires) por medio del Decreto $32.347 \mathrm{del} 30 \mathrm{de}$ Noviembre de $1944^{20}$ generando un áspero cruce entre las autoridades del Poder Ejecutivo y los miembros de la Suprema Corte de Justicia que devino en el juicio político y posterior alejamiento de los miembros de la Corte. Este incidente generó postergaciones en la puesta en funcionamiento de los juzgados de la Capital

15 BÉJAR, María Dolores. El régimen fraudulento. La política en la provincia de Buenos Aires,1930-1945. Buenos Aires: Siglo XXI, 2005.

16 ASCOLANI, Adrián. El Sindicalismo rural en la Argentina. De la resistencia clasista a la comunidad organizada (1928-1952). Bernal: UNQ, 2009.

17 HOBSBAWM, Eric. El mundo del trabajo. Estudios históricos sobre la formación y evolución de la clase obrera. Barcelona: Crítica, 1987.

18 El Poder Legislativo dio cuenta también de la existencia del conflicto. A pesar de la negativa de muchos legisladores y las dificultades de los partidos que en mayor o menor medida poseían una masa mayor de votantes proletarios para imponerse en ambas cámaras, fueron promovidas leyes laborales y de seguridad social tendientes a favorecer a los trabajadores. La presión de los sindicatos con mayor grado de organización fue fundamental para el logro de los avances legislativos como indican la cantidad de leyes referidas al trabajo en los ferrocarriles o en el transporte marítimo, que antes de la ampliación de los derechos sociales ocurridas principalmente durante el primer peronismo, habían logrado notables ventajas con respecto al resto de la clase obrera. Véase PANETTIERI, José. Las Primeras leyes obreras, CEAL, Buenos Aires, 1985.

19 La relación entre Perón y los trabajadores se ha convertido en el núcleo de las explicaciones sobre el surgimiento del peronismo. No se pretende aquí reseñar los debates sobre este punto, aunque si es necesario señalar que la llegada del peronismo impacto en la expansión de los derechos laborales y la sanción de convenios colectivos a casi todas las ramas de la producción. Toda la acción legislativa de la Secretaría de Trabajo y Previsión desde el 4 de Junio de 1943 hasta la asunción de las autoridades en 1946 fue reafirmada por el Congreso de la Nación mediante la Ley 12.921 (AAVV, circa 1948).

$20 \mathrm{El}$ anteproyecto de la Justicia del Trabajo sobre el que se basó el decreto fue presentado por Eduardo R. Stafforini (jefe de la división asesoría jurídica) y participaron en la redacción César Martínez Vivot y el sr. Luis A. Rufo. El 1 de julio de 1944 este anteproyecto fue elevado a Perón quien se desempeñaba en esos momentos como Secretario de Trabajo y Previsión. Justicia del trabajo. Organización, competencia y procedimiento. Buenos Aires: Imprenta del Congreso Nacional, 1944. 
Federal hasta que el reinicio de las actividades del Congreso de la Nación dotó al decreto con fuerza de ley.

Por el carácter federal de la república, la jurisdicción de los juzgados del trabajo quedaron limitadas a aquellas circunscripciones sobre las que el Congreso de la Nación tenía potestades de Legislatura: es decir la Capital Federal y los territorios nacionales, quedando la potestad para poner en marcha instituciones similares en manos de las autoridades provinciales. En la provincia de Buenos Aires, la justicia del trabajo fue producto de la Ley Provincial 5.178 de 1947 sancionada bajo el impulso del gobernador Domingo Mercante (“el Corazón de Perón”), y la puesta en marcha de los Tribunales del Trabajo se dio en 1948, cuando se nombraron los primeros jueces del trabajo y se dotó a estos de estructura administrativa. La forma institucional varió considerablemente de aquellas finalmente impuestas en la ciudad de Buenos Aires, con una conformación colegiada, aunque al igual que su similar porteña mantuvo la gratuidad y su carácter oral. ${ }^{21}$

Así, mientras el Poder Ejecutivo piensa en la resolución de los conflictos en términos colectivos, ya sea mediante instituciones corporativistas o mediante la apelación a actores colectivos - básicamente a los sindicatos y las asociaciones patronales -, dentro del Poder Judicial se concretó la creación de una institución destinada a individualizar a los actores. Tanto en la forma que adquirió en la Capital Federal como en la provincia de Buenos Aires los Juzgados y Tribunales del Trabajo individualizaban a los actores en pugna. ${ }^{22} \mathrm{Si}$ en el ámbito del Poder Ejecutivo se pensaba en torno a colectivos identificables como clases antagónicas que debían ser armonizadas en pos de solucionar un conflicto inherente a la relación laboral, en el Poder Judicial se solucionaba un conflicto determinado entre el actor tal y el demandado cual. ¿Cuáles son los límites de esta individualización a la hora de pensar los conflictos de la justicia del trabajo en términos de clase? ¿Es posible sostener esta instancia como colectiva a pesar de su pretendida función individualizadora?

\section{Límites a la individualización de la Justicia del Trabajo.}

\section{El límite doctrinal}

La ley 5178 que estableció la justicia del trabajo para la provincia de Buenos Aires rezaba en su artículo $6^{\circ}$ que "los Tribunales del Trabajo conocerán: a) En única instancia y en juicio oral y público de los conflictos jurídicos individuales del trabajo que tengan lugar entre empleadores y trabajadores o aprendices"23. El trabajador, a la hora de defender en instancia judicial sus derechos, debía presentarse como actor en tanto persona física. Pero este mecanismo procesal no es suficiente para concebir a la Justicia del Trabajo como un organismo individualizante.

Un primer límite a esta pretensión se encuentra en la génesis misma del Derecho del Trabajo que asignaba derechos y obligaciones diferentes a

21 STAGNARO, Andrés. "Los debates de la ley 5178 de creación de los Tribunales del Trabajo en la provincia de Buenos Aires". In: PANELLA, Claudio (comp.). El Gobierno de Domingo A. Mercante en Buenos Aires (19461952). Un caso de peronismo provincial, Tomo V, La Plata: Instituto Cultural de la Provincia de Buenos Aires, 2011.

22 NIETO, Agustín. "Conflictividad obrera en el terreno de la justicia laboral. la experiencia de las obreras/os del pescado, 1950-1955”. In: Segundo Congreso de Estudios sobre el Peronismo (1943-1976), Caseros, 2010.

23 Anales de Legislación Argentina 1947, Tomo VII, La Ley, Buenos Aires, 1948. Pp.1072. 
trabajadores y empleadores. Si la tradición civil sobre la que se había construido el edificio institucional jurídico de la república Argentina concebía a sus ciudadanos como formalmente iguales ante la ley y regulaba las relaciones entre privados por medio del contrato libremente contraído, el Derecho del Trabajo se construyó sobre principios diferentes. Al colocar la venta del trabajo, en tanto mercancía, bajo la protección de la figura de la locación de servicios, el Código Civil Argentino inscribía la posible legislación del trabajo bajo las formas doctrinarias de la tradición civil. Esto significaba que se fundamentaba la relación laboral en términos privados, anteponiendo el contrato como legalización de la relación entre los individuos y no sujetos, por lo tanto, a la ley como expresión de una voluntad general emanada del Estado. ${ }^{24}$

Pero a pesar de encontrar su origen dentro de la tradición civil, en el desarrollo y creciente autonomía del Derecho Laboral se abordó la relación entre privados como una cuestión pública y a los contratantes como esencialmente desiguales, inscribiéndola en el Derecho Público. Se asumía que el trabajador no vendía en condición de igualdad su trabajo como cualquier otra mercadería, sino que la desigual relación de poder entre patrón y empleado le permitía al primero imponer las condiciones de la venta del trabajo y esto restringía la libertad de una de las partes. Esta desigualdad en el plano real de la relación económica entre ambos contratantes debía ser regulada de manera tal de, mediante la desigualdad jurídica y la protección de la parte más débil, contrabalancear la desigualdad. Desigualar para igualar es el principio del Derecho del Trabajo.

La adscripción, entonces, del Derecho del Trabajo al derecho público quiebra la posibilidad de la existencia de un contrato entre individuos y sujeta por medio de la ley en términos diferenciales a los polos de la relación laboral. Esta diferenciación ya incluye a los trabajadores como sujetos de derechos colectivos, y no como simple poseedores de una mercancía factible de ser vendida entre privados.

El mismo artículo $6^{\circ}$ ya citado hace referencia que para poder ser parte (tanto parte actora como demandada) había que formar parte de uno de los dos polos de la relación laboral. En definitiva, aunque se propusiese resolver desavenencias entre particulares, la Justicia del Trabajo lidiaba con sujetos que respondían a una particular relación en donde el derecho los desigualaba no en tanto poseedores de una naturaleza distinta, sino como parte de un vinculo relacional en donde se transaba con la venta de un bien de diferente al resto de las mercaderías.

\section{La Justicia del Trabajo como recurso colectivo}

A pesar de que la Justicia del trabajo refiriese a los conflictos individuales, muchas veces tomaban parte como actores varios trabajadores reclamando el mismo derecho. Esta presentación colectiva, si bien después los jueces resolvían caso por caso, podía tener dos vías: la presentación de dos o más trabajadores como promotores de una misma demanda o la agrupación procedimental. La segunda variable implicaba que el tribunal decidía resolver diferentes demandas

24 Las distinciones del contrato como expresión de un derecho natural y fundante de la relación entre individuos en la sociedad civil, y la ley como emanada del estado y por lo tanto derecho positivo, pueden seguirse en el breve análisis de Norberto Bobbio. Allí el autor realiza la historización de lo que denomina la "gran dicotomía" entre público/privado, y derivada de ésta, ley/contrato. BOBBIO, Norberto. Estado, gobierno y sociedad. Por una teoría general de la política. México D.F.: FCE, 1994. 
en un solo veredicto y acuerdo ${ }^{25}$ debido a cuestiones de orden procesal. Por lo general ésto implicaba que varios actores habían presentado distintas demandas, pero promovidas contra un mismo patrón y por el mismo causal (cumplimiento de convenio por ejemplo). Cuando la cuestión de fondo a tratar es la misma también se llevaba, por cuestiones procedimentales, a una sola resolución aplicada a todas las causas.

La segunda vía era la presentación de varios trabajadores como actores en una misma causa o por una misma causa. Este parece haber sido el caso de varios empleados de panaderías, ${ }^{26}$ que piden el cumplimiento de la resolución del 11 de Marzo de 1949 del director de Acción Social Directa, ${ }^{27}$ Hugo Mercante, ${ }^{28}$ ratificada por el Ministro de Trabajo y Previsión, que fijaba nuevas normas de trabajo y otorgaba un aumento de sueldo a los empleados de panaderías de la Capital Federal y de $60 \mathrm{Km}$ a la redonda. ${ }^{29}$ La particularidad de la resolución radicaba en que la medida era retroactiva, y por otro lado no se trataba de un convenio colectivo de trabajo, sino de una medida adoptada por la Dirección de Acción Social Directa y avalada por el ministerio del que dependía administrativamente. Las demandas, redactadas todas en términos similares reclaman que la norma sea cumplida en su totalidad. Un dato por demás interesante en estas causas es que la Carta Poder ${ }^{30}$ se firma el mismo día, un 20 de Marzo de 1950, y a favor de los mismos abogado, los Dres. Sigwald y Cerruti Costa. Implica esta sincronía al menos la existencia de reuniones de coordinación en la que los abogados obtuvieron la anuencia para presentar la demanda. Si la institucionalización de la Justicia del Trabajo implicaba la individualización del conflicto, la propia experiencia de los trabajadores oponía la construcción de tácticas colectivas.

En su argumentación, Sigwald y Cerruti Costa sostienen que la parte patronal - los propietarios de los establecimientos panificadores - han ya aceptado en

25 Los expedientes judiciales laborales dan cuenta del proceso de una demanda en la justicia: se presentaba la demanda, dando lugar a la contestación por parte del demandado y una nueva contestación del actor (como se identifica a quine inicia la demanda), después de cumplimentados estos pasos se pasaba a la recolección de las pruebas (citación de testigos, confección de pericias contables, recolección de testimonios). Una vez resueltas estas instancias se convocaba a las partes a una audiencia donde se solían hacer las objeciones o presentar testimonios (prácticamente no hay registros de los mismos por ser de carácter oral) y de allí el tribunal comenzaba las deliberaciones de donde se desprendía el acuerdo, el veredicto y la sentencia. En caso de que no hubiese ninguna apelación allí concluía la causa, sino seguía la vía de la Suprema Corte de Justicia de la provincia de Buenos Aires.

26 En total constituyen 6 causas judiciales que involucran a 7 trabajadores (Francisco Cinelli, Féliz González, Enrique Lignasi, Enrique López, Jesús Tato, Miguel Moreno, José María Castillo) y 6 empresas del rubro de panificados.

27 La Dirección de Acción Social Directa constituía parte del Ministerio de Trabajo y Previsión. Como tal era parte integrante del conglomerado de instituciones con capacidad de intervenir en las relaciones laborales mediante la sanción de diversas normas referidas a las condiciones de trabajo. En este sentido, es menester recordar que en la etapa peronista el mundo del trabajo fue objeto de múltiples regulaciones legales en las que se incluyen la sanción de los Derechos del Trabajador -incluidos en el texto constitucional reformado en 1949-, leyes varias, resoluciones, decretos y convenios colectivos que tendieron a superponer diferentes normativas que constituyeron una verdadera maraña legal.

28 Se trataba del hermano del gobernador de la provincia de Buenos Aires Domingo A. Mercante, que gobernó entre 1946 y 1952, importante dirigente del primer peronismo. Ambos poseían fuertes vínculos sindicales por relaciones familiares con sindicalistas del gremio ferroviario que permitió incluso oficiar de interventores del gremio Unión Ferroviaria en 1943. Veáse: GASPARRI, Mario R. "Mercante y los ferroviarios. Una relación trascendente y necesaria para la consolidación de la gestión de Perón al frente de la Secretaria de Trabajo y Previsión". In: PANELLA, Claudio (comp.). El gobierno de Domingo A. Mercante en Buenos Aires (1946-1952). Un caso de peronismo provincial. Tomo I, La Plata: Instituto Cultural de la Provincia de Buenos Aires, 2005.

29 Por desgracia, no han quedado registros de la resolución en los expedientes que permitan indagar sobre los cambios en las condiciones de trabajo y el aumento salarial que se proponía.

30 La Carta Poder era la que habilitaba a los abogados a llevar adelante la causa. Sin la presentación de una Carta Poder firmada por las partes el proceso no tenía valor legal alguno. 
forma tácita la resolución al adoptar las nuevas condiciones laborales y realizado el aumento de sueldo correspondiente. Pero esta aceptación, según los abogados de los actores, ha sido reconocida solo parcialmente, pues no se ha cumplido con el pago de los sueldos de febrero y marzo que se debía realizar en forma retroactiva.

Estas causas promovidas por los peones de panadería serán desistidas en su mayoría - al menos las que se conservan, pero se puede inferir que lo mismo ocurre con causas similares iniciadas en ese tiempo - por los actores. Y aquella que, como la causa catalogada con el número 10 del paquete 102,31 si llega a obtener una resolución por parte del tribunal laboral, encuentra en los jueces una respuesta negativa a sus reclamos al aceptar éstos que la resolución de la Secretaría de Acción Social Directa carecía de imperio legal y no podía modificarse de forma unilateral las condiciones de trabajo y salariales de los Convenios Colectivos. De todas maneras, cuando los actores desisten del juicio, siempre alegan que se debe a resoluciones negativas para casos similares por parte del mismo tribunal que está juzgando su caso, o por resoluciones negativas del otro tribunal que tenía asiento en la ciudad de La Plata, el tribunal $n^{\circ} 2.3^{32}$ Esta verdadera oleada litigiosa da cuenta de la existencia de canales previos de carácter colectivo que el proceso individualizador de la Justicia del Trabajo no puede desandar. El hecho de que los trabajadores hayan firmado la Carta Poder el mismo día indica la existencia de una instancia organizativa - tal vez promovida por los abogados - en donde se tomó la decisión de acudir a la Justicia del Trabajo.

La presencia de los mismos abogados puede sugerir también que se trató de un acción llevada adelante por medio de una organización preexistente. Si bien los sindicatos y gremios no podían constituirse como partes actoras ya que sólo podían hacerlo personas físicas, se puede rastrear la presencia de las organizaciones en las causas. Los sindicatos desarrollaron otras funciones de aquellas que generalmente han recibido la atención de la historiografía ${ }^{33}$ que terminaron por matizar el aspecto individualizante de la justicia laboral.

De los 42 expedientes que se conservan para el Tribunal del Trabajo $n^{\circ} 1$ entre los años 1948 - año que comienza a funcionar - y 1955, 15 registran la presencia de sindicatos de manera activa en diferentes papeles. Como curiosidad, y tal vez producto de la casualidad, sólo una causa en donde la presencia del sindicato es visible llegó a una conciliación previa al dictado del veredicto, de un total de 13 causas que lograron un acuerdo. En un fuero donde la finalidad era la conciliación, ${ }^{34}$ una correlación como esta habilita la pregunta de si la intervención sindical no atentaba contra el objetivo mismo de la justicia laboral. Resulta interesante pensar que posiblemente el acompañamiento sindical dotase de fuerza al reclamo del trabajador. Que la presencia de la fuerza sindical hiciese posible el sostenimiento de la demanda ante el patrón, mientras que la ausencia del sindicato dejaba al trabajador ante una situación en donde la desigualdad fundante de la relación se

31 Las causas en las que se ventilan los casos de los peones panaderos se encuentran resguardadas en el Departamento Histórico de la Suprema Corte de Justicia de la provincia de Buenos Aires (en adelante $\mathrm{DH}$ ) bajo el siguiente orden: DH 102/8, DH 102/9, DH 102/10, DH 102/11, DH 102/18, DH 102/19.

32 Según se desprende de los considerandos de la nota de desistimiento del juicio.

33 Los estudios sobre los sindicatos tienden a privilegiar su rol en las huelgas, los vaivenes de su propia conformación o de la política interna o su lugar dentro del entramado de dotación de servicios sociales (salud, turismo).

34 El artículo 26 de la ley 5178 dice: "Los jueces podrán intentar la conciliación en cualquier momento del procedimiento”. Anales de Legislación Argentina, Tomo VII, La Ley, Buenos Aires, 1948, pp. 1074. La conciliación privada entre las partes también daba por concluido el proceso. La cuestión de la obligatoriedad de la conciliación fue objeto de debates en la Legislatura previo a la sanción de la ley. Véase STAGNARO, Andres. op.cit. 
le hacía más evidente y el arreglo aparecía como una buena opción, aun incluso cuando fuese sabedor de que sus derechos podían prevalecer.

La presencia de los sindicatos, excluidos de la posibilidad de pleitear directamente, tomaba diversas formas. Podía ser el comienzo del recorrido ante la violación de un derecho, ser testigo privilegiado en la causa, ser un apoyo material al trabajador por medio de la dotación de profesionales - principalmente abogados - e incluso otorgar las estrategias legales para enfrentar al patrón.

Otra causa da cuenta que el 20 de Abril de 1949 la empresa Saint Hnos decidió cambiar las condiciones de trabajo de los vendedores ambulantes de sus productos - chocolates, helados y golosinas en general. Les solicitó a los vendedores que se declarasen como compradores del producto como respuesta a un logro del Sindicato de Empleados y Obreros de la Alimentación. El sindicato había logrado que la autoridad administrativa ${ }^{35}$ reconociese a los trabajadores como obreros o empleados ${ }^{36}$ y que los representantes patronales firmasen el convenio colectivo $n^{\circ} 80$ en Marzo de 1949. El reconocimiento fue producto de una acción sindical conjunta de los vendedores ambulantes de la empresa demandada y los vendedores de la empresa Noel \& Cía - también dedicada al mismo rubro alimenticio -, que incluyó también demandas en los Juzgados Laborales de la Capital Federal e intervención en la Delegación Regional de la Secretaría de Trabajo y Previsión con sede en la ciudad de La Plata.

El motivo por el cual pleiteaban los vendedores ambulantes ya había inspirado la acción conjunta de 55 trabajadores contra la misma empresa en la Capital Federal y dado origen a la causa "Amnie Aboul Rahman y otros c/ Saint Hnos S.A." del Juzgado ${ }^{\circ} 30$ del Trabajo de la Capital Federal en la que vendedores en cines, calles, etc. demandaron el pago de aguinaldo, vacaciones y aumentos de emergencia del decreto ley 33.302, procurando con ello ser declarados empleados de la empresa ${ }^{37}$. Los antecedentes propuestos por los abogados de ambas partes y los retomados por los jueces en el Acuerdo dan cuenta de la existencia de otro proceso análogo. En el Acuerdo sobresale la causa del Tribunal del Trabajo $n^{\circ} 2$ de La Plata, Secretaría 4, caratulada "López Dalmiro Ulises y otros c/ Noel y Cia Ltda. - Indemnización por despido”. Las razones que habían motivado esta causa eran las mismas. Es interesante observar que se trataba de una causa impulsada simultáneamente a la que se está tratando aquí que tiene como destinatario otra empresa del mismo rubro.

En la instancia administrativa, la causa había sido directamente encarada por el sindicato como persona jurídica. El contacto más fluido de los sindicatos con las autoridades del Poder Ejecutivo y el carácter marcadamente corporativo permitía que la acción fuera encarada por el sindicato en lugar de por los trabajadores de forma individual. En el marco judicial, la función fue otra, básicamente la de dotar de contenido la causa y promoverla mediante otros mecanismos. A este rol buscado

35 Las autoridades administrativas son las que dependían de organismos del Poder Ejecutivo.

36 Por lo tanto se convertían en sujetos de derechos y esto los habilitaba para reclamar la protección de la creciente legislación del período. El reconocimiento constaba en el expediente $n^{\circ} 13.439$ de 1948 Letra A de la Secretaría de Trabajo y Previsión-Delegación Regional La Plata. Dicho expediente era solicitado como prueba por parte del abogado de la parte actora en su demanda. La existencia de una resolución previa por parte de las autoridades administrativas y la posterior demanda en el fuero judicial da cuenta de la incapacidad de la Secretaría de Trabajo y Previsión de declarar vinculante sus resoluciones. A diferencia de las sentencias judiciales, las resoluciones administrativas eran optativas en su cumplimiento.

37 DH 102-1, "Raffino Juan y otros c/Saint Hnos S.A. s/ despido, etc", foja 40 y sig. La causa del Juzgado $n^{\circ} 30$ del Trabajo de la capital Federal fue resuelta de manera negativa para los trabajadores, ya que fueron declarados comerciantes y por lo tanto sin relación de dependencia con la empresa. 
por el mismo sindicato se sumó los requeridos por la justicia. En conocimiento de la existencia del convenio colectivo y sabiendo el rol del sindicato como promotor de las acciones en la instancia administrativa, el abogado de la empresa demandada, el Dr. Miramon Pourtales, decide convocar al secretario general del sindicato, el Sr. José Sucar Tau, como testigo. Esta táctica obligó al secretario general a reconocer la existencia de contratos comerciales entre la empresa Saint Hnos. y dos casas comerciales de la ciudad de La Plata. Así, se desarticulaba el pedido de los trabajadores de mantener relación laboral directa con la empresa demandada.

La existencia de causas simultáneas y de carácter colectivo - agrupaban a todos los trabajadores de una empresa ${ }^{38}$ - habla a las claras de la existencia de una voluntad colectiva más allá del impulso individual de los trabajadores. La consecución de los hechos propone pensar el conflicto en términos de simultaneidad de acción de los trabajadores avalados por el Sindicato de Empleados y Obreros de la Alimentación de acciones en distintos planos para logar el mismo fin. Causas judiciales, firma de convenios colectivos, requerimientos a la autoridad administrativa: hacen evidentes la conformación de una estrategia sindical que buscaba aprovechar el contexto político que se mostraba discursiva e institucionalmente favorable a los trabajadores.

Este contexto ponía a disposición del sindicato otros caminos para hacer oír su descontento con la situación en la que se encontraban algunos de sus asociados. La disponibilidad tanto de la instancia administrativa, como de la instancia judicial, evitaba tener que recurrir exclusivamente a la huelga como medio de protesta. La huelga como método de lucha implica la movilización de la fuerza social acumulada del sindicato sin garantías de resolución favorable, sin contar que genera la puesta en juego del capital político, tanto hacia los otros actores intervinientes como así mismo para dentro mismo de los trabajadores. En cambio, las opciones puestas a disposición por medio de la instancia administrativa y sobre todo la Justicia del Trabajo permitían llevar adelante estrategias más conservadoras, en tanto que el capital puesto en juego era menor.

Pero lo más llamativo de esta causa no es la opción tomada por el sindicato de avalar y, se puede suponer, de consensuar la presentación de sus afiliados como damnificados ante la justicia, sino la apropiación, por parte del sindicato y los trabajadores, de una herramienta de acción individual y tornarla colectiva. La acción judicial de carácter individual es trasmutada en una acción sindical de carácter colectivo, parte de una estrategia más amplia del sindicato para hacer valer los derechos de sus afiliados.

Esta presencia sindical puede ser un buen indicativo de los límites individualizantes de la Justicia del Trabajo. Más aún teniendo en cuenta que constituían un paso importante en la trayectoria de los trabajadores hacia los estrados judiciales. La procura por los derechos de los trabajadores no era un mecanismo tan sencillo como aquél que establecía la ley. Ésta habilitaba a cualquier trabajador a presentarse como damnificado y entablar demanda contra su patrón. Sin embargo, la construcción del polo trabajo no fue tampoco un paso sencillo para estos trabajadores que tuvieron en primer término que ser reconocidos como tales a fines legales. Este es un proceso por demás interesante porque implica

38 Ya quedó consignado el carácter individual de la justicia laboral. Sin embargo, por cuestiones de sencillez procesal cuando el demandado - en este caso la empresa Saint Hnos - era el mismo se permitía a los distintos actores accionar de manera conjunta. Si bien esto no rompía con la tendencia individualizante, ya que el tribunal fallaba caso por caso, permitía otro tipo de apropiación colectiva de la experiencia de la justicia. 
que el trabajador individual se reconozca a sí mismo como parte de un colectivo - definido en primera instancia en relación a su lugar en el entramado productivo que porta ciertos derechos que los distinguen de otros colectivos. En el reclamo y ejercicio de dichos derechos es donde podemos también percibir el quiebre del proceso de individualización impuesto por la institución judicial.

La universalización de los derechos del trabajador propuestas por el peronismo, que constituyó a los trabajadores en el centro de su lógica discursiva, 39 es necesaria mas no suficiente para pensar en la construcción de un sujeto colectivo. Esta situación era especialmente importante para aquellos trabajadores que no estaban vinculados a sus patrones por medio de empleos formales, sino que vivían de la venta esporádica de su fuerza de trabajo. Así, changarines y cuentapropistas buscaban ser reconocidos como parte de un colectivo -los trabajadores sujetos de derechos- que los habilitaba a reclamar en tribunales los beneficios que las leyes obreras otorgaban. Esta búsqueda de inclusión legal en el polo trabajo de la relación laboral es otra de las formas en que la Justicia del Trabajo rompe con su molde de individualización. Tal fue el caso del estibador Alfredo Desio quien decidió, en 1949, iniciar acciones legales contra la empresa Murchinson Estibajes por el pago de las indemnizaciones correspondientes a un accidente inculpable y despido..$^{4}$ La estrategia legal de Desio y sus abogados fue la de considerarse en tanto constitutivo del polo trabajo de la relación laboral, es decir como parte del sujeto colectivo trabajadores que gozaba de derechos. No se presenta Desio como un ciudadano individual cuyos derechos fueron lesionados por otro ciudadano, sino que lo hace en tanto que los derechos lesionados son derechos colectivos, de los trabajadores. Este límite doctrinal que imponía el derecho del trabajo a la individualización procesal es fundamental para comprender la importancia de los tribunales del trabajo bonaerenses en tanto arena de un conflicto de características colectivas.

\section{Algunas reflexiones}

¿Cómo asumir la presentación de los trabajadores ante la Justicia del Trabajo como una forma de acción colectiva y no individual? Aun dando cuenta de los límites de la individualización que como institución imponía el proceso de la justicia laboral, la presencia de trabajadores individuales ante el estrado judicial no puede ser pensado exclusivamente dentro de marcos analíticos individualizantes o centrados en la acción racional de un individuo como ejes explicativos. Ya sugería Durkheim en su estudio sobre el suicidio en Francia que una acción de índole tan privada y ligada al individuo como la decisión de quitarse la vida no podía explicarse sólo por "constitución orgánico-psiquica de los individuos" ${ }^{41}$ sino que se debe a causas sociales y por este motivo constituir un fenómeno colectivo. Entonces que causas sociales explican la afluencia de los trabajadores a la Justicia del Trabajo, y más allá de si constituye un fenómeno colectivo (del cual no caben aquí dudas), ¿es una acción colectiva?

El tipo de conflicto analizado no reviste las características de un conflicto

39 GENÉ, Marcela. Un mundo feliz. Imágenes de los trabajadores en el primer peronismo, 1946-1955, Buenos Aires, FCE-Universidad de San Andrés, 2008.

40 DH 102-4 Desio Alfredo c/ Murchison Estibajes S.R.L. s/ haberes, Año 1949.

41 DURKHEIM, Emile. El Suicidio. Buenos Aires: Ediciones del Libertador, 2004, pp. 127. 
tendiente al cambio social, entendiendo éste como el reemplazo de una sociedad por otra. Sin embargo, se trata de una conflictividad permanente que apunta hacia el centro de la disputa entre el capital y el trabajo. La acción judicial asumía que se trataba de resolver las disputas surgidas de una relación social y no ya del simple intercambio de mercaderías sobre la que se sostenía la forma jurídica del fetiche de la mercancía en la tradición civil. Se trata de una forma más del mismo conflicto, en la medida en que las disputas se dan en torno a los derechos surgidos de la relación (de explotación) entre el trabajador y su patrón, y este conflicto sólo puede ser entendido colectivamente.

No es posible, comprendiendo a los conflictos en la Justicia del Trabajo como conflictos colectivos, construir la explicación de los conflictos a través exclusivamente de las acciones de los individuos. No hay dudas de que los trabajadores que acuden a la Justicia del Trabajo lo hacen con un previo análisis de sus posibilidades. Y este análisis conlleva la elección de un fin y los medios para llevarlo a cabo. Pero esta elección no es común a todos los individuos envueltos en una relación laboral e incluso no todos tienen las mismas posibilidades a la hora de optar por los medios. Este tipo de conflicto en donde pesan las motivaciones individuales pero sin negar el carácter colectivo del mismo se presentan como una ocasión ideal para repensar el concepto de la agencia histórica de los individuos. La lucha es llevada adelante por un individuo en una institución individualizante como la Justicia del Trabajo bonaerense, pero responde a un conflicto que se desprende no ya de una relación entre individuos privados sino que es consecuencia de la desigualdad en la que se funda dicha relación y que define incluso el carácter de la sociedad misma. La agencia histórica permite abordar a los actores en pugna sin dejar de lado su posición concreta en el entramado social.

Esta posibilidad que abre el concepto de agencia histórica permite reconstruir las trayectorias individuales e interrelacionarlas en configuraciones sociales (¿marco estructural?). Al contemplar la agencia histórica como concepto clave de la explicación se logra romper con una dicotomía entre la explicación basada exclusivamente en el individuo o aquellas que buscan hacerlo exclusivamente mediante la estructura. El concepto de agencia, definido como las capacidades estructurales de los individuos, ${ }^{42}$ permite desnaturalizar una distinción que las ciencias sociales han tomado ya como real entre el individuo y la estructura. Ya Norbert Elías Ilamó la atención sobre los problemas que implica en términos del análisis sociohistórico perder de vista en entramado social en el que operan los individuos. Del mismo modo que las acciones individuales no pueden ser explicadas exclusivamente sobre las bases estructurales de una sociedad, la sociedad misma no puede ser explicada sin recurrir a los individuos que la conforman ni mediante la consideración de la suma de los individuos como partes autónomas. ${ }^{43}$

Trasladadas estas reflexiones al caso de la Justicia del Trabajo, es evidente, como ya se remarcó, el impulso individual de los trabajadores a acudir a la justicia. Pero esta posibilidad es producto de una mejora en las capacidades estructurales de los trabajadores. La creación de una institución directamente ligada a resolver cuestiones tan sensibles al colectivo del trabajo, como las formas y el valor en las que se intercambian el trabajo, no podía sino interpelar a toda la comunidad laboral. Retomando la cuestión de los límites, la interpelación misma que el Derecho del Trabajo realiza sobre los sujetos los cataloga dentro de un colectivo que posee

42 CALLINICOS, Alex. Making History. Agency, Structure and Change in Social History. London-Leiden: Brill, 2004.

43 ELÍAS, Norbert. La Sociedad de los individuos. Barcelona: Península, 1990. 
características distintivas según el polo de la relación que encarnen. En el caso de los trabajadores los interpela justamente como trabajadores y no ya sólo como ciudadanos dotados de los mismos derechos y obligaciones. Esta interpelación, aun pensada como ampliación de los derechos de ciudadanía, es una ampliación ligada a la existencia de una comunidad determinada, es decir que se identifican como parte de un colectivo.

Si bien esta identificación nos permite pensar a los trabajadores que acuden a la Justicia del Trabajo como parte de una misma comunidad, no alcanza para sostener que se trata de acciones colectivas. Según Hobsbawm, a la clase obrera "su experiencia de las cosas laborales les demuestra todos los días que ha[n] de obrar colectivamente. Pero aun su labor colectiva requiere, para ser efectiva, estructuración y dirección". ${ }^{44}$ La referencia es clara y alude a los sindicatos u organizaciones de carácter clasista que buscasen activamente la promoción y defensa de los trabajadores como colectividad. La existencia de este tipo de organizaciones formales garantiza la permanencia de las formas duraderas de acción colectiva. Pero aunque los sindicatos sin dudas se encuentran en la trayectoria del trabajador en la procura de sus derechos (muchas causas judiciales eran promovidas por los abogados provistos por los sindicatos o era en el local sindical donde el trabajador recurría en primer término para buscar resarcimiento) y a pesar de contar con personería jurídica ${ }^{45}$ su presencia como parte en juicio era explícitamente excluida por la Ley 5178 de la provincia de Buenos Aires.

Si bien la acción colectiva, en su definición minimalista, implica ciertamente la existencia de la voluntad de individuos -ya definidos como agentes- de coordinar sus acciones en búsqueda de un fin, la presencia de una organización formal le otorga permanencia en el tiempo. Pero excluidos los sindicatos el trabajo de pensar la acción judicial como acción colectiva requiere una explicación en donde el concepto mismo de agente será central.

Definida la agencia como el ejercicio de la capacidad estructural de los individuos se puede sostener que la voluntad (individual) de presentarse como parte de un conflicto implica el análisis de la situación y la elección del medio para logar el fin deseado. En este camino la Justicia del Trabajo, ¿implica una transformación de dichas capacidades estructurales? ¿su estructura organizativa puede ser pensada como una organización formal que promueva la acción colectiva? La primera pregunta no parece encontrar demasiadas complicaciones. No hay dudas de que la creación de un canal más para llevar adelante el conflicto, aun cuando se trate de una institución estatal, cambia las condiciones estructurales sobre las cuales sostener y promover el conflicto, aun cuando se trate de un cambio que promueve no ya un nivel de aspiración de cambio social profundo, sino a la satisfacción de demandas inmediatas concretas.

En lo que respecta al tipo de organización la respuesta implica desandar algunos lugares comunes sobre el lugar del Estado en el conflicto. Una idea común sobre el Estado y el conflicto de clases la expresa historiográficamente Eric Hobsbawm derechos y obligaciones. 
en las ciudades preindustriales, o institucionalizado como "rituales de la rebelión" (para emplear la frase iluminadora de Max Gluckman) o de otras formas; pero a veces no puede serlo. El Estado normalmente legitimará el orden social mediante el control del conflicto de clases dentro de un sistema estable de instituciones y valores, permaneciendo ostensiblemente por encima y fuera de ellos (el rey remoto como "fuente de justicia"), y al hacer esto perpetuará una sociedad que de otra forma se vería desgarrada por sus tensiones internas. ${ }^{46}$

Esta premisa implica aceptar que el conflicto de clases funciona como una olla donde se va acumulando presión hasta estallar e implica creer que esta presión puede ser liberada en dosis tales de no desestabilizar el sistema en su totalidad. Asumir esto es herir de muerte la creencia el concepto de agencia histórica. Ya no se trata del ejercicio de los poderes estructurales históricamente limitados o potenciados, sino la existencia de umbrales de aceptación o rechazo de la explotación que pueden ser definidos de antemano por los sectores dominantes. La Justicia del Trabajo podría ser catalogada como un ritual de la rebelión en tanto institución estatal que se coloca discursivamente ostensiblemente por encima y fuera del conflicto. Pero la existencia de una institución ligada y nacida bajo la intención de evitar los desgarros sociales no se puede sostener que fuese una válvula de escape a las tensiones entre el capital y el trabajo. En tanto institución basada en domesticar mediante la individualización un conflicto colectivo que tiene potencialmente la salida de llevar a un cambio social, otorga al mismo tiempo la posibilidad concreta de ser reconocida como un posibilidad más del mismo conflicto, potencialmente ampliando las capacidades estructurales de una clase por sobre la otra.

Recebido em: 24/04/2013

Aprovado em: 29/09/2013

46 HOBSBAWM, Eric. op. cit, p. 96. 